\title{
An observational study to compare WHO modified partogram and paperless partogram
}

\author{
Nidhi Thakur, Bawa Ram Bhagat, Vishav Dev Singh Dadwal, Rachana, Preeti \\ Corresponding author: Dr. Nidhi Thakur, Resident, Department of Obstetrics and Gynaecology, \\ Government medical college, Jammu, India; Email: nidhithakur14764@gmail.com
}

Distributed under Attribution-Non Commercial - Share Alike 4.0 International (CC BY-NC-SA 4.0)

\begin{abstract}
Objectives: This study aimed to compare WHO modified partogram and paperless partogram in the effective management of labor. Methods: This hospital-based prospective observational study included 200 pregnant women. They were randomized into Group A $(n=100)$ who were monitored with paperless partogram during active labor and Group B ( $\mathrm{n}=100)$ who were monitored with WHO modified partogram. Resident doctors compared the partographs on the basis of user friendliness (1-10), teachability (1-10), and overall usefulness (1-10). Statistical Package for Social Sciences (SPSS) version 21.0 was used for statistical analysis. P-value of $<0.05$ was taken as statistically significant. Results: Baseline characteristics were similar in Group A and Group B ( $>>0.05)$. Among residents, 57\% expressed difficulty with plotting and maintaining WHO Modified partograph. WHO Modified partograph had significantly lower user friendliness score $(5.83 \pm 0.75$ vs. $9 \pm 0.89, \mathrm{P}=0.0001)$, teachability score $(7 \pm 0.63$ vs. $9.5 \pm 0.55$, $\mathrm{P}=0.003)$, and overall usefulness $(7.5 \pm 0.55$ vs. $8.83 \pm 0.41, \mathrm{P}=0.005)$ than paperless partograph. Conclusion: Paperless partogram was found to be better compared to WHO partogram with respect to user friendliness, teachability, and overall usefulness. It appears to be promising to replace the WHO partograph for monitoring of labor.
\end{abstract}

Keywords: Labor, management, partograph.

Partograph is a graphic recording of several events of labor plotted against time. These events are progress of labor and salient features in the mother as well as fetus. ${ }^{1}$ It is a cost-effective health intervention, which helps to monitor labor and in taking correct decisions for the currently increasing maternal mortality rate (WHO 2017 reported 295,000 deaths during pregnancy and after childbirth). ${ }^{2}$ Friedman in 1954 developed partograph based on his observations on labors of women in Zimbabwe. ${ }^{3}$ This was modified by Philpott and Castle in 1972, who introduced the concept of alert and action lines. ${ }^{4}$ These were the foundation for development of earliest WHO partograph, the Composite partograph, which was further modified in 2000 (by removing the latent phase) to result in the WHO modified partograph; universal adoption of modified partograph was recommended by WHO as part of the Safe Motherhood
Initiative (that was launched in 1987). ${ }^{5-7}$

In spite of the favorable findings of improved maternal outcomes that result from correct partograph, it is underutilized and misused, specifically in low resource countries. The cause of this low usage has been influenced by many factors, including lack of knowledge and proper training, poor availability of partographs, negative interpretations of the partograph, high patient load, insufficient staff, lack of supervision, and negative attitudes in few health workers. ${ }^{5}$

Continuous labor monitoring and the provision of urgent treatment to overcome complications are most important to prevent adverse obstetric outcomes associated with childbirth. In 2010, Debdas suggested the "Paperless Partograph" is simple, without graph, less time taking, twostep calculation that recognizes slow progress of labor and

Received: $8^{\text {th }}$ December 2020, Peer review completed: $2^{\text {nd }}$ February 2021, Accepted: $5^{\text {th }}$ February 2021.

Thakur N, Bhagat BR, Dadwal VDS, Rachana, Preeti. An observational study to compare WHO modified partogram and paperless partogram. The New Indian Journal of OBGYN. 2022; 8(2): 161-65. 
The New Indian Journal of OBGYN. 2021 (January-June);8(2)

aids in taking correct decisions. ${ }^{6}$ The Paperless partograph is an easy method, which only involves calculating the expected time of delivery (ETD). It recognizes slow progress of labor, time required for intervening and terminating labor, or need of transferring a woman to a higher center with facilities for cesarean section (CS). ${ }^{8}$

Thus, present study was done to compare WHO modified partogram and paperless partogram in the effective management of labor on the basis of deliveries in relation to alert and action line/ETDs, mode of delivery, perinatal outcome, user friendliness, and factors of noncompliance of partographs.

\section{Methods}

This was a hospital based prospective observational study conducted for a period of 1 year. The approval was taken from hospital ethical committee. After an informed and written consent, total 200 pregnant women who attended labor room for delivery and who fulfilled inclusion criteria were selected. Women with obstetric complications, such as preterm labor, previous CS, postdated pregnancy, cephalopelvic disproportion, antepartum hemorrhage, severe pre-eclampsia/eclampsia, malpresentation, multiple pregnancy, fetal distress, intrauterine fetal death, intrauterine growth restriction (IUGR), premature rupture of membranes (PROM) etc., and those with medical complications like anemia, hypertension, diabetes, and immunocompromised states were excluded.

They were randomly allocated into two groups: Group A ( $n=100$, who were monitored with paperless partogram during active labor) and Group B $(\mathrm{n}=100$, who were monitored with WHO modified partogram). Detailed demographic data and history of all patients were taken.

The plotting of the partograph was started when cervical dilatation reached $4 \mathrm{~cm}$ with regular painful uterine contractions. At the end of each partograph, outcome of labor was recorded. Resident doctors working on shift duties in the labor room, who were trained about the use of either partographs (Paperless partograph and WHO modified partograph), randomly used these partographs for monitoring labor and based on their personal experience gave scores to each of the partographs on the basis of user friendliness (1-10), teachability (1-10), and overall usefulness (1-10). In all partographs, completeness was checked.

Statistical analysis: Categorical variables were presented in number and percentage (\%), and continuous variables as mean $\pm \mathrm{SD}$. By independent t-test, quantitative variables were compared between the two groups, and qualitative variables by using Chi-Square test/Fisher's Exact test. P-value $<0.05$ was considered statistically significant. The data was entered in MS EXCEL spreadsheet; Statistical Package for Social Sciences (SPSS) version 21.0 was used for analysis.

\section{Results}

There was no significant difference between group A and group B in baseline characteristics, such as age $(26.49 \pm 2.82$ vs. $26.44 \pm 3.4, \mathrm{P}=0.915$ ), systolic blood pressure (SBP) $(\mathrm{mmHg})(116.62 \pm 6.49$ vs. $116.48 \pm 6.99, \mathrm{P}=0.883)$, diastolic blood pressure (DBP) (74.98 \pm 4.97 vs. $76.04 \pm$ 5.07, $\mathrm{P}=0.137)$, pulse rate $(\mathrm{bpm})(81.36 \pm 5.23$ vs. $82.78 \pm$ $5.93, \mathrm{P}=0.074)$, body mass index (BMI) $(24.94 \pm 2.02$ vs. $24.32 \pm 2.84, \mathrm{P}=0.077)$, temperature $\left({ }^{\circ} \mathrm{F}\right)(96.98 \pm 2.35$ vs. 96.4 $\pm 2.19, \quad \mathrm{P}=0.072$ ), period of gestation(weeks) (38.86 \pm 1.32 vs. $38.79 \pm 0.87, \mathrm{P}=0.204)$, gravidity $(\mathrm{P}=0.866)$, parity $(\mathrm{P}=0.966)$, and uterine contractions ( $/ 10$ minutes $)(\mathrm{P}=0.494)$. In groups $\mathrm{A}$ and $\mathrm{B}$, majority of the cases were gravida 2 $(47.00 \%$ vs. $48.00 \%)$ and nullipara $(48.00 \%$ vs. $47.00 \%)$,

\begin{tabular}{|c|c|c|c|}
\hline Baseline characteristics & Group A & Group B & P value \\
\hline $\begin{array}{l}\text { Age(in years) } \\
\text { Range } \\
\text { Mean } \pm S D\end{array}$ & $\begin{array}{l}22-36 \\
26.49 \pm 2.82\end{array}$ & $\begin{array}{l}21-33 \\
26.44 \pm 3.4\end{array}$ & 0.915 \\
\hline $\begin{array}{l}\text { Systolic blood pressure } \\
\text { Range } \\
\text { Mean } \pm \text { SD }\end{array}$ & $\begin{array}{l}\text { Hg) } \\
100-132 \\
116.62 \pm 6.49 \\
\end{array}$ & $\begin{array}{l}100-132 \\
116.48 \pm 6.99\end{array}$ & 0.883 \\
\hline $\begin{array}{l}\text { Diastolic blood pressure } \\
\text { Range } \\
\text { Mean } \pm \text { SD }\end{array}$ & $\begin{array}{l}\mathbf{m H g}) \\
70-86 \\
74.98 \pm 4.97 \\
\end{array}$ & $\begin{array}{l}70-86 \\
76.04 \pm 5.07\end{array}$ & 0.137 \\
\hline $\begin{array}{l}\text { Pulse rate(bpm) } \\
\text { Range } \\
\text { Mean } \pm \text { SD }\end{array}$ & $\begin{array}{l}72-92 \\
81.36 \pm 5.23\end{array}$ & $\begin{array}{l}74-90 \\
82.78 \pm 5.93\end{array}$ & 0.074 \\
\hline $\begin{array}{l}\text { Body mass index }\left(\mathbf{k g} / \mathbf{m}^{2}\right) \\
\text { Range } \\
\text { Mean } \pm \mathrm{SD}\end{array}$ & $\begin{array}{l}22-27.78 \\
24.94 \pm 2.02\end{array}$ & $\begin{array}{l}20.18-29.19 \\
24.32 \pm 2.84\end{array}$ & 0.077 \\
\hline $\begin{array}{l}\text { Temperature }(\mathbf{F}) \\
\text { Range } \\
\text { Mean } \pm \text { SD }\end{array}$ & $\begin{array}{l}94-98.6 \\
96.98 \pm 2.35\end{array}$ & $\begin{array}{l}92.4-98.6 \\
96.4 \pm 2.19 \\
\end{array}$ & 0.072 \\
\hline $\begin{array}{l}\text { Period of gestation(weel } \\
\text { Range } \\
\text { Mean } \pm \text { SD }\end{array}$ & $\begin{array}{l}38.83-40 \\
38.86 \pm 1.32\end{array}$ & $\begin{array}{l}37-40 \\
38.79 \pm 0.87\end{array}$ & 0.204 \\
\hline $\begin{array}{l}\text { Gravidity } \\
\text { Primigravida } \\
\text { Gravida } 2 \\
\text { Gravida } 3\end{array}$ & $\begin{array}{l}42(42.00 \%) \\
47(47.00 \%) \\
11(11.00 \%)\end{array}$ & $\begin{array}{l}39(39.00 \%) \\
48(48.00 \%) \\
13(13.00 \%)\end{array}$ & 0.866 \\
\hline $\begin{array}{l}\text { Parity } \\
\text { Nulliparous } \\
\text { Para } 1 \\
\text { Para } 2\end{array}$ & $\begin{array}{l}48(48.00 \%) \\
44(44.00 \%) \\
8(8 \%)\end{array}$ & $\begin{array}{l}47(47.00 \%) \\
44(44.00 \%) \\
9(9 \%)\end{array}$ & 0.966 \\
\hline $\begin{array}{l}\text { Uterine contractions }(/ \mathbf{1} \\
0 \\
1 \\
2 \\
3 \\
4 \\
\text { Mean } \pm \text { SD }\end{array}$ & $\begin{array}{l}\text { inutes) } \\
0(0.00 \%) \\
6(6.00 \%) \\
57(57.00 \%) \\
29(29.00 \%) \\
8(8.00 \%) \\
2.39 \pm 0.72 \\
\end{array}$ & $\begin{array}{l}1(1.00 \%) \\
9(9.00 \%) \\
46(46.00 \%) \\
35(35.00 \%) \\
9(9.00 \%) \\
2.42 \pm 0.82 \\
\end{array}$ & 0.494 \\
\hline
\end{tabular}


and most of the cases $(57.00 \%)$ had two uterine contractions (/10 minutes) (table 1$)$. neonatal intensive care unit (NICU) admission (5.00\% vs. $7.00 \%, \mathrm{P}=0.552)$ (table 4).

\begin{tabular}{|c|c|c|c|c|}
\hline \multirow{2}{*}{ Delivery } & \multicolumn{2}{|c|}{ Group } & \multirow{2}{*}{ Total } & \multirow{2}{*}{$\begin{array}{l}\mathbf{P} \\
\text { value }\end{array}$} \\
\hline & $\mathbf{A}$ & B & & \\
\hline Delivery before alert line/ETD & $78(78 \%)$ & $77(77 \%)$ & $155(77.50 \%)$ & \\
\hline Delivery between Alert and Action line/ETD & $16(16 \%)$ & $18(18.00 \%)$ & $34(17 \%)$ & 0.898 \\
\hline Delivery after Action line/ETD & $6(6.00 \%)$ & $5(5.00 \%)$ & $11(5.50 \%)$ & \\
\hline Total & $100(100.00 \%)$ & $100(100.00 \%)$ & $200(100.00 \%)$ & \\
\hline
\end{tabular}

Maximum number of patients delivered before alert line/ETD in groups A and B (78\% vs. $77 \%)$. Number of patients who delivered between alert and action line/ETD in group $\mathrm{A}$ and $\mathrm{B}$ were $16 \%$ and $18 \%$, respectively. $6 \%$ of patients in group A and 5\% of patients in group B delivered after action line/ETD. Deliveries in both the groups were comparable $(\mathrm{P}=0.898)$ (table 2$)$.

\begin{tabular}{llll} 
Table 3: Comparison of mode of delivery & & \\
\hline Variable & A & B & $\begin{array}{l}\text { P } \\
\text { value }\end{array}$ \\
\hline Mode of delivery & & \\
$\begin{array}{l}\text { Spontaneous vaginal } \\
\text { LSCS }\end{array}$ & $\begin{array}{l}89(89.00 \%) \\
6(6.00 \%)\end{array}$ & $\begin{array}{l}82(82.00 \%) \\
11(11.00 \%)\end{array}$ & 0.352 \\
Assisted vaginal (Instrumental) & $5(5.00 \%)$ & $7(7.00 \%)$ & \\
\hline Indications of LSCS & $1(16.67 \%)$ & $5(45.45 \%)$ & \multirow{2}{*}{0.323} \\
AFD & $3(50.00 \%)$ & $2(18.18 \%)$ \\
Non descent of head & $2(33.33 \%)$ & $4(36.36 \%)$ & \\
NPOL & & \\
\hline LSCS - Lower segment caesarean section, AFD - Acute fetal distress, NPOL \\
- Non progression of labor.
\end{tabular}

There was no significant difference in group A and B in terms of mode of delivery [Spontaneous vaginal: $89.00 \%$ vs. $82.00 \%$; lower segment cesarean section (LSCS) $(6.00 \%$ vs. $11.00 \%)$; assisted vaginal (instrumental) $(5.00 \%$ vs. $7.00 \%)$ $(\mathrm{P}=0.352)$ ], and indications of LSCS [acute fetal distress (AFD) $(16.67 \%$ vs. $45.45 \%)$, nondescent of head $(50.00 \%$ vs. $18.18 \%)$, non-progression of labor (NPOL) $(33.33 \%$ vs. $36.36 \%), \mathrm{P}=0.323$ ] (table 3).

\begin{tabular}{llll}
\multicolumn{3}{l}{ Table 4: Comparison of perinatal outcome } \\
\cline { 2 - 3 } Variable & \multicolumn{1}{c}{ Group } & P \\
& A & B & \\
\cline { 2 - 3 } Birth weight (in kgs) & & & \\
$<2.5$ & $4(4.00 \%)$ & $3(3.00 \%)$ & \\
$2.5-3$ & $87(87.00 \%)$ & $78(78.00 \%)$ & \\
$3.1-3.5$ & $5(5.00 \%)$ & $11(11.00 \%)$ & 0.239 \\
$>3.5$ & $4(4.00 \%)$ & $8(8.00 \%)$ & \\
Mean \pm SD & $2.82 \pm 0.33$ & $2.94 \pm 0.39$ & \\
\hline Apgar score at 1 minute & $9.5 \pm 0.96$ & $9.46 \pm 1.06$ & 0.939 \\
Apgar score at 5 minutes & $9.74 \pm 0.68$ & $9.76 \pm 0.65$ & 0.831 \\
\hline NICU admissions & & & \\
No & $95(95.00 \%)$ & $93(93.00 \%)$ & 0.552 \\
Yes & $5(5.00 \%)$ & $7(7.00 \%)$ & \\
\hline
\end{tabular}

No significant difference was present in groups A and B with respect to mean birth weight $(2.82 \pm 0.33$ vs. 2.94 $\pm 0.39, \mathrm{P}=0.239$ ), mean Apgar score at 1 minute (9.5 \pm 0.96 vs. 9.46 $\pm 1.06, \quad \mathrm{P}=0.939)$, mean Apgar score at 5 minutes (9.74 \pm 0.68 vs. $9.76 \pm 0.65, \mathrm{P}=0.831)$, and requirement of
Difficulty with plotting and maintaining WHO modified partograph was expressed by $57 \%$ of the residents, whereas, the paperless partograph was observed to be much easier to plot and monitor by residents. Factors of non-compliance in WHO modified partograph were high patient load (38.60\%), time consuming (33.33\%), less staff (22.81\%), and complex graph (5.26\%) (figure 1).

Table 5: Comparison of usefulness and ease of two partographs

\begin{tabular}{llll}
\hline \multirow{2}{*}{ Variables } & \multicolumn{2}{c}{ Group } & P value \\
\cline { 2 - 3 } & $\mathbf{A}$ & $\mathbf{B}$ & \\
\hline User friendliness & $9 \pm 0.89$ & $5.83 \pm 0.75$ & 0.0001 \\
Teachability & $9.5 \pm 0.55$ & $7 \pm 0.63$ & 0.003 \\
Overall usefulness & $8.83 \pm 0.41$ & $7.5 \pm 0.55$ & 0.005 \\
\hline
\end{tabular}

The two partographs were scored by the resident doctors for the following: user friendliness, teachability, and overall usefulness. As compared to group A, group B had significantly lower user friendliness score $(5.83 \pm 0.75$ vs. $9 \pm 0.89, \mathrm{P}=0.0001)$, significantly lower teachability score $(7 \pm 0.63$ vs. $9.5 \pm 0.55, \mathrm{P}=0.003)$, and significantly lower overall usefulness $(7.5 \pm 0.55$ vs. $8.83 \pm 0.41$, $\mathrm{P}=0.005)$ (table 5).

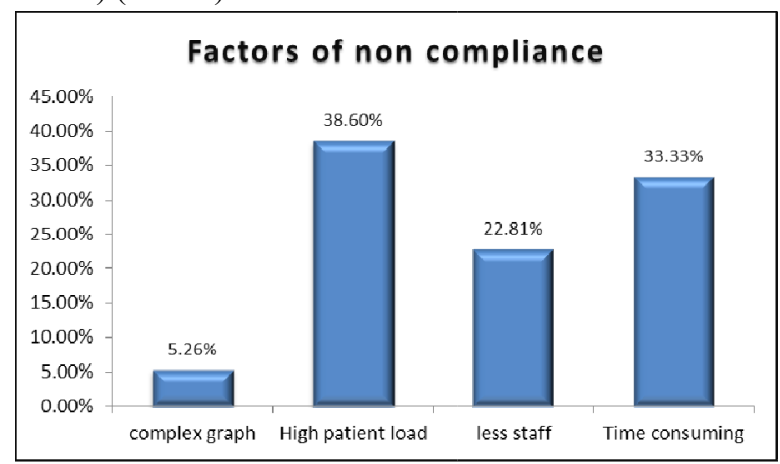

Figure 1: Factors of non-compliance of WHO partograph

\section{Discussion}

For decreasing the rate of maternal and perinatal morbidity and mortality, it is required to monitor and appropriately manage the progress of labor. ${ }^{7}$ Partogram, a early warning system and serves in early decision making related to the augment-ation, termination of labor, and if essential transfer to higher center for proper management. It acts an effective way for sharing technical information related to the labor progress between caregivers' team. ${ }^{8}$ As recommended by WHO, WHO modified partogram should be universally applied; however, it is hardly used and when bedside tool, depicts the progress of labor and assists as an 
used is not interpreted correctly. The paperless partogram, which was proposed by Dr Debdas, is an easy, simple and less time taking process for monitoring labor and helping in correct decision making. ${ }^{6}$ In this context, this hospital based prospective analytical study was conducted to compare WHO modified partogram and paperless partogram in the effective management of labor.

It was observed that most of the patients delivered within alert line/ETD (i.e. 78\% of patients in group A and 77\% of patients in group B). Similar findings were reported by Veena et al $(83 \%$ in paperless group and $73 \%$ in $\mathrm{WHO}$ modified group), Deka $\mathrm{G}$ et al ${ }^{9}$ (83\% in paperless partograph and $77 \%$ in WHO group), and Faswila M et al ${ }^{10}$ ( $83 \%$ of patients in paperless group and $74 \%$ of patients in WHO group), as maximum number of patients delivered within alert line/ETD. In the present study $16 \%$ of patients in group A and $18 \%$ of patients in group B had their deliveries between alert and action line/ETD. Similar percentage of patients in other studies like Veena $\mathrm{L}$ et al ${ }^{1}$, (14\% in paperless group and $18 \%$ in WHO group), Deka G et al, ${ }^{9}$ (15\% in paperless group and $18.5 \%$ in WHO group) and Faswila $\mathrm{M}$ et al, ${ }^{10}$ (7\% in group A and $9 \%$ in group B) had their deliveries between alert and action line/ETD which is consistent with our study. Also $6 \%$ of patients in group $\mathrm{A}$ and $5 \%$ of patients in group B delivered after action line/ETD. Results are in concordance with studies done by Veena $\mathrm{L}$ et al, (3\% in paperless group and $6 \%$ in WHO group), Deka $\mathrm{G}$ et al, ${ }^{9}$ (4\% in paperless group and $9 \%$ in WHO group) and Faswila $\mathrm{M}$ et al ${ }^{10}$.

The success of spontaneous delivery was $89 \%$ of patients in group $\mathrm{A}$ and $82 \%$ of patients in group $\mathrm{B}$, which was similar to that reported in studies by Veena L et al ${ }^{1}$, where $85 \%$ cases monitored by paperless partograph and $79 \%$ monitored by WHO modified partograph had spontaneous vaginal delivery. Deka $\mathrm{G}$ et $\mathrm{al},{ }^{9}$ also found that $88.5 \%$ of cases monitored by paperless partograph and $85 \%$ of cases monitored by WHO partograph had spontaneous delivery. In present study, the rate of caesarean section was $6 \%$ in patients monitored by paperless partogram versus $11 \%$ in WHO group. In study by Faswila et al, ${ }^{10}$ rate of $13 \%$ caesarean sections with the paperless partograph and $18 \%$ in WHO modified partograph was observed. Another study by Deka G et al, ${ }^{9} \mathrm{CS}$ was required in $6 \%$ of patients monitored by paperless partograph and $10.5 \%$ cases monitored with WHO partograph.

The average Apgar score after 1 minute $(9.5 \pm 0.96$ vs. $9.46 \pm 1.06)$ and 5 minutes $(9.74 \pm 0.68$ vs. $9.76 \pm 0.65)$ were comparable in groups A and B $(\mathrm{P}>0.05)$. Similar results were seen in study done by Fatouh E et al, ${ }^{11}$ Mishra PC et al, ${ }^{12}$ and Giri DK et al. ${ }^{13}$ Requirement of NICU was similar in groups $\mathrm{A}$ and $\mathrm{B}$ in the present study ( $5 \%$ vs. $7 \%, \mathrm{P}=0.552)$; Mohammed et al, ${ }^{14}$ reported that no newborn need to admit to NICU, which reveals the positive effect of paperless partogram on neonatal outcome.

Paperless partograph was preferred by $57 \%$ of the residents as they found it much easier to plot and monitor, and expressed difficulty with plotting and maintaining WHO Modified partograph. Similar results were seen in a study done by Deka G et al, ${ }^{9}$ where $66.6 \%$ preferred the paperless partograph; findings was supported by Fatouh E et al, ${ }^{11}$ who reported that $75 \%$ nurses preferred the paperless partograph. Even Veena L et al, ${ }^{1}$ also found that $66.7 \%$ residents expressed difficulty with the WHO Modified partograph. Debdas $^{6}$ mentioned that the WHO modified partograph didnot meet the requirement of the organization for appropriatet technology, was not adapted to local requirements, and was not accepted by individuals who used it; also, it was considered as complicated by several skilled birth attendants as most of them were not that much qualified. On analysis of partographs, it was observed that the WHO modified partograph had lower user friendliness, teachability, and overall usefulness scores than paperless partograph, which was in accordance with the findings of study by Sharma $\mathrm{R}$ et al, ${ }^{15}$ who also reported that paperless partograph had higher user friendliness and teachability scores. In terms of the overall usefulness score, no significant difference was noted as both partographs were found to be equally effective in prevention of prolonged labor and also both showed comparable requirement of augmentation and operative intervention. Veena L et al ${ }^{1}$ and Deka et al ${ }^{9}$ found higher user friendliness, teachability scores for paperless partograph and comparable overall usefulness as they were equally effective in detecting abnormal labor.

Thus, based on findings of present study and above mentioned previous studies, it can be inferred that when compared with the WHO partograph, paperless partograph was observed to be more user friendly and preferred by the residents. One of the limitations of the study was that although the sample size of the study was good, but being a single center hospital based study, the results of the efficacy of WHO partograph and paperless partograph may need further validation. 
The New Indian Journal of OBGYN. 2021 (January-June);8(2)

\section{Conclusion}

Paperless partograph has great potential to prevent prolonged labor as it is simpler, less time consuming and graphless. Maintenance of paperless partograph is easy, and even those with limited formal training can easily plot it because no graph need to be plotted and there is no curve to monitor. Lesser complications are associated with it, and it needs less time to be performed.

Therefore, it is safe as well as effective, and can be utilized as an option for WHO modified partograph, specifically in areas that have high number of patients and lack of manpower with much ease, acceptability, and usefulness. Further studies should be conducted with the paperless partograph even at the grass root levels of health care staff, such as skilled birth attendants, for evaluating its effectiveness at the community level in different populations.

\section{Conflict of interest: None. Disclaimer: Nil.}

\section{References}

1. Veena L, Sarojini, Anagondanahalli P, Prakash, Suchitra. Study to compare between paperless partogram and modified who partogram in management of labour. Int J Reprod Contracept Obstet Gynecol. 2018; 7: 99103.

2. Trends in maternal mortality: 2000 to 2017 : estimates by WHO, UNICEF, UNFPA, World Bank Group and the United Nations Population Division. Geneva: World Health Organization; 2019.

3. Friedman E. Graphic analysis of labour. Am J ObstGynaecol. 1954; 68: 1568-75.

4. Philpott RH. Graphic records in labour. Br Med J. 1972; 4: 163-5.

5. Lavender T, Hart A, Smyth RM. Effect of partogram use on outcomes for women in spontaneous labour at term. Cochrane Database Syst Rev. 2012; 8: CD005461.

6. Debdas AK. Paperless partogram. 41st annual scientific session 2008. Sri Lanka College Obst Gynecol 2008;1(1): 124 .

7. World Health Organization. Maternal mortality. Available from: http://www.who.int/ mediacentre/ factsheets/ fs348/en/ [Accessed August 2020].

8. Ogwang S, Karyabakabo Z, Rutebemberwa E. Assessment of partogram use during labour in
Rujumbura Health Sub District, Rukungiri District, Uganda. Afr Health Sci. 2009; 9(1): S27.

9. Deka G, Sharma R, Das GC. The paperless partograph can it be effective to replace the WHO modified partograph. Int J Reprod Contracept Obstet Gynecol. 2016; 5: 452-5.

10. Faswila M, Rao SB. Comparative study of user friendliness of paperless partogram compared to WHO partogram in preventing prolonged labour. Int J Reprod Contracept Obstet Gynecol. 2019; 8: 229-33.

11. Fatouh E, Ramadan S. Effect of using Paperless Partogram on the Management and Outcome of Labour and the Nurses' Opinion. J Education Practice. 2015; 6(8):17-23.

12. Mishra PC, Nayak L. Validity of paperless Partogram A new simple clinical tool for prevention of prolonged and obstructed labor. Int J Currt Res. 2016; 8(12): 43887-90.

13. Giri DK, Nayak L, Dalai DK. Comparison of procedure and predictability between WHO partogram and paperless partogram. JMSCR. 2019; 7(7): 611-4.

14. Mohammed MA, Fouly HA, Abbas AM, Mostafa MF. Effect of using the paperless partograph versus the original partograph on labor outcomes in Women's Health Hospital. Assiut Scientific Nursing J. 2018; 6(13): 64-7.

15. Sharma R. The Paperless partograph - The new userfriendly and simpler tool for monitoring labour. IOSRJDMS. 2015;14(11): 39-44.

\section{Nidhi Thakur ${ }^{1}$, Bawa Ram Bhagat ${ }^{2}$, Vishav Dev Singh Dadwal $^{3}$, Rachana ${ }^{4}$, Preeti $^{5}$}

${ }^{1}$ Resident, Department of Obstetrics and Gynaecology, Government medical college, Jammu, India; ${ }^{2}$ Associate Professor, Department of Obstetrics and Gynaecology, Government medical college, Jammu, India; ${ }^{3}$ Resident, Department of Medicine, Government medical college, Jammu, India;

${ }^{4}$ Resident, Department of Obstetrics and Gynaecology, Government medical college, Jammu, India; ${ }^{5}$ Resident, Department of Obstetrics and Gynaecology, Government medical college, Jammu, India. 